\title{
A Study on Problems in Teaching of Automobile Utilization Specialty and Improvement Measures therefore
}

\author{
Liang Jiao \\ Baoji Vocational Technology College Baoji Shaanxi 721001
}

\begin{abstract}
Key words: Automobile utilization specialty, Teaching problems, Improvement measures.
\end{abstract}
\begin{abstract}
As the state lays more and more stress on vocational education, the teaching of automobile utilization specialty becomes more and more scientific and rational. In practical teaching process, however, we should realize that there are problems in the teaching of automobile utilization specialty, and improvement measures should be taken. This paper aims to, in combination with the actual situation, analyze the problems in teaching of automobile utilization specialty, and put forward improvement measures, with a hope to facilitate teaching quality improvement.
\end{abstract}

\section{Introduction}

In recent years, the competition of the automobile industry becomes more and more intense, automobile enterprises face larger and larger pressure. In competition process, to obtain more advantages, the updating of automobile technology significantly accelerates, and new automobile products are released more and more frequently. Thus, the updating of vocational education knowledge on the automobile industry remarkably quickens. Besides, China's vocational education has been constantly reformed in recent year. All these factors greatly influence the teaching of automobile knowledge. In the teaching process of most vocational colleges, practice is carried out in classroom, which just helps consolidate the basic knowledge and ideas of students. Thus, students' thinking becomes changeless and fixed. Teachers tend to pay attention to whether students have completed the given practical steps, and ignore the deep connotation of practice and research.

\section{Analysis of Problems in Teaching of Automobile Utilization Specialty}

\section{Dull Teaching Mode}

Presently, most vocational colleges recognize the role and important position of practice curriculum in the teaching of automobile utilization specialty. Nevertheless, there are still many problems in the process of teaching design and classroom teaching. Firstly, in respect of teaching design, teachers fall behind the development of times, impart obsolete contents, fail to efficiently utilize teaching resources and carry out teaching based on the actual situation, are unable to help students fully understand and grasp advanced theoretical knowledge and operative skills, and greatly reduce students' enthusiasm and passion for learning. Secondly, in the process of teaching activity arrangement, the teachers of automobile utilization specialty cannot follow the requirements of vocational education reform, but stick to traditional teaching mode, are capable of employing the advanced teaching methods, lack the competence of practical operation, and are unable to arouse students' enthusiasm for learning. The advanced teaching modes, such as small class teaching, MOOC, cooperation and inquiry learning are just applied to demonstration lesson and teaching design competition. It is thus clear that the advanced teaching modes are not made full use of, and teachers lack the competence of practical application. 


\section{Outdated Teaching Equipment}

Practical teaching is an indispensable link in the teaching of automobile utilization specialty. Through practical training, students can further consolidate their theoretical knowledge and professional skills, understand and grasp the working principle of automobile and breakdown maintenance skills better, and constantly temper their practical ability. In real teaching process, however, the above requirements cannot be explicitly put forward. Under limited conditions, many vocational colleges are badly-equipped, cannot keep pace with the development of times and provide good practice opportunity to students, so that the quality of practical teaching cannot be guaranteed.

\section{Incompetence of Teachers in respect of Professional Teaching}

Teachers play an important part in the teaching of automobile utilization specialty, acting as organizer, instructor and evaluator of teaching activities. Presently, a prominent problem in teaching of automobile utilization specialty is the incompetence of teacher. Most teachers are newly-graduated undergraduate or postgraduate. Although they have a solid theoretical knowledge foundation, they lack practice opportunity, and are incapable of practice. Such teachers are superior in thesis writing, scientific research and position promoting, but they lack experience of practical teaching of automobile utilization specialty and work experience exchange. Under such circumstances, the theoretical teaching and practical teaching of automobile utilization specialty of vocational colleges disconnect, and the teaching reform capability is low, which largely hinders the teaching quality improvement of the whole automobile utilization specialty.

\section{Analysis of Measures for Teaching Improvement of Automobile Utilization Specialty}

\section{Selection and Ordering of Teaching Contents}

The curriculum installation of automobile utilization specialty in western developed countries all follow the teaching sequence from simple to difficult, from automobile parts, structure, principle to maintenance and repair, and students seldom can touch comprehensive automobile dismantlement and repair, comprehensive automobile inspection, and trouble removal. With the development of times, the requirements for automobile personnel have significantly changed. What automobile talents face is a complex. Thus, the course contents and course system establishment of automobile utilization specialty should be on a global basis, student should be instructed to learn the connection of automobile parts on the whole first so as to master the overall dismantlement, inspection, repair and maintenance of automobile, and learn to use related tools and equipment so as to learn to independently solve problem in the process of automobile inspection and repair. Education of professional particulars should follow that students have fully learned about and understood automobile utilization specialty, so that students' ability of trouble shooting and removal and problem solving can be improved. The design of teaching contents should follow the principle of carrying out teaching from globality to locality and then to globality. Only proper course contents and teaching sequence of automobile utilization specialty are defined, student can have a comprehensive knowledge and understanding of the integral structure and performance of automobile, know the position of each assembly of automobile, completely comprehend the connection between and dismantlement method of each assembly, basically master the common repair tools in automobile repair, learn to independently perform inspection and repair, and truly appreciate the means and skills of automobile maintenance. Based on such teaching contents and sequence, the consciousness of safe education and quality can be fully implemented, and students' communicative and cooperative ability can be improved, greatly helpful to improving students' practical ability.

\section{Design of Scientific Teaching Scenario}

According to the cognitive theory, every individual has language understanding ability, logical thinking ability, visual space ability, human body movement ability, music rhythm comprehensive 
ability, interpersonal communication ability and self-cognition ability, and these abilities vary from person to person. Therefore, in the teaching process of automobile utilization specialty, to fully arouse students' learning motivation and interests, we should make comprehensive consideration and analysis, and scientifically design teaching scenario, to stimulate students' abilities to the large extent. Teaching scenario includes theoretical teaching scenario, professional course teaching scenario and professional practical teaching scenario. Theoretical teaching scenario mainly covers professional theoretical knowledge and literacy teaching, which need a furnished classroom and multimedia only. Professional course teaching scenario is an important part of teaching scenario design, for which the teaching area, automobile equipment maintenance area, and vehicle trouble removal area should be provided. The teaching area is mainly provided for teachers for preparing lessons and teaching materials, the maintenance and inspection area is required to be provided with different automobile equipment for the need of manual operation of students based on the actual teaching demands, and the vehicle trouble removal area is required to be provided with a finished automobile and testing equipment, where students can erect automobile equipment and dismantle them for trouble inspection with the help of a lifter. Professional practical teaching scenario is divided into teaching area, reception area, practice area, tool and material area, and student activity area. In general case, scenario-oriented teaching is carried out in the professional practical teaching scenario, of which the contents are in correspondence with the theoretical teaching contents, namely asking students to experience the whole automobile maintenance and repair procedure from automobile receiving, operation, self-testing, delivery, to treatment.

\section{Implementation Teaching Courses}

Presently, most teachers of vocational colleges applaud the reform of vocational colleges, but their execution in the reform is poor, and they haven't created any demonstration case of teaching. Besides, mot teachers themselves were educated in the traditional teaching mode, so the tradition teaching idea took strong root in their heart. Thus, experiential teaching, cooperative learning teaching, problem instruction and other new teaching modes just become a mere formality, so that teachers cannot effectively guide students to change their passive learning style. Though new teaching modes are adopted, the classroom atmosphere is not driven, and students' initiative is not aroused. In view of this case, we need to deeply analyze the reasons, timely take measures to solve this problem, and implement courses well.

\subsubsection{News}

The first step is to assign teaching tasks. Teaching tasks should be assigned in combination with the actual situation, in which the focal points and difficulties should be highlighted. Besides, the tasks should be close to actual production and life that students are expected to experience in future. For example, a user needs to have the lubricants and filter of his Honda which has run $80,000 \mathrm{~km}$ replaced. In this case, students' should know the key points of replacement and the matters needing attention in the process of replacement well. The second step is to set teaching objectives. Before formally implementing teaching, teachers should introduce the focal points and difficulties of teaching in detail to students, so that students can have a comprehensive knowledge of the teaching objectives, and teaching requirements. In every teaching link, students should be informed of the teaching methods and steps, and provided with related learning resources, such as automobile model, structure, components and parts, etc. The third step is to scientifically divide study groups. Before teaching, students should be divided into groups in accordance with the synergetic development idea to promote group members to extensively cooperate and communicate. The differences of students should be stressed in the processing of grouping, to guarantee the scientificity and rationality of grouping, and promote group members complement each other's advantages. Besides, it should be ensured that every group member undertakes definite tasks, so that all group members can participate, the interaction among group members can be enhanced, and students' occupational ability can be improved. The fourth step is presentation. Teachers can present the overall process of automobile engine dismantlement and equipment replacement to students, and raise questions based on 
corresponding tasks to enhance students' concentration. The last step is error correction. Teachers can play a video of automobile lubricants and filter replacement and ask students to identify errors in the video based on what they learned, arrange students to interact and discuss with each other, and let students freely voice their opinions and suggestions in an open orderly and harmonious environment, to develop students' critical thinking skills, teach students to find solutions to problems, and raise students' sense of achievement.

\section{Plan Implementation}

The specific implementation contents are: asking students to answer questions based on group discussions and analysis, letting students master the sequence and principle of automobile engine lubricants replacement through discussions, and teaching students to inspect and maintain automobile engine; after the foregoing steps, asking students to make a plan of engine lubricants replacement on by-group basis, discussing with student on their replacement plans, giving suggestions on revision to students, and making group discussions again. In this process, in order to prevent students spending too much time discussing, it is recommended to employ analog simulation software for verification and replacement. In actual operation, it is hard for students to avoid problems; teachers should help them correct errors timely, so that students will not repeat such problems in future. In the process of plan implementation, teachers also should supervise students' operation and response to tasks in judgment process, and constantly improve task design in combination with the actual situation. It is recommended to shoot a video to record students' actual operation if conditions permit, to lay a foundation for effect evaluation.

\section{Effect Evaluation}

Comprehensive evaluation on the performance of each group should be made based on the completeness and quality of task fulfillment, and teachers can guide students to learn about their problems by comparing the video of students' operation with the standard operation video. The members of the group who achieve good evaluation result can be asked to make a speech, to share their experience and insight, and give suggestions on revision to other groups. Teachers can make comments on the speech, and give award to the group.

\section{Conclusion}

As the society put forward higher requirements for automobile talents, vocational colleges should set such objectives of automobile talents training as letting students master solid automobile theoretical knowledge, have a good knowledge of automotive failures, and grasp basic automobile inspection and maintenance skills. To this end, teachers are required to highlight the operability and practice of vocational education, and lay stress on the cultivation of students' communicative ability, cooperative ability, logical reasoning ability, and problem solving ability.

\section{References}

[1] Wang Zirui. Exploration and Attempt of University-Industry Cooperation in Teaching of Automobile Utilization Technology Specialty--Development Project of Practical Curriculum Oriented by Occupational Skill Training and Testing. Intelligence. 2015(36)

[2] Liang Ting. Discussions on Reform and Practice of Automobile Utilization Technology Specialty in Vocational Colleges. Small and medium-sized enterprise management and science and technology (next ten-day). 2015(12)

[3] Zhao Jianning. Exploration and Practice of Teaching Reform of Automobile Utilization Technology Specialty in Vocational Colleges. Career Horizon. 2014(02)

[4] Wu Lianlian. Discussions on Automobile Utilization Technology Talents Training Mode based on Automobile 4S Shops. Vocational Technology. 2013(07) 
[5] Wang Jun, Sun Xuguang. Brief Discussions on How to Improve the Practice Skill and Level of Vocational College Teacher--Automobile Utilization Technology Specialty. Jiaotong Zhiye Jiaoyu. 2012(01)

[6] Editorial Department. A Distinctive Automobile Maintenance and Repair Training School-Sino-US Joint Venture Suzhou Jiewei Technology Training Center. Light Vehicles. 1995(06)

[7] Wang Xiaohui. Positioning and Training of Senior Professional Automobile Maintenance and Repair Talents. Journal of Nantong Vocational \& Technical Shipping College. 2006(03)

[8] Hu Bin, Luo Xin, Chen Yongcheng, Mei Weijiang. Thoughts of Improving Teaching Quality of Tractor and Automobile Schools. Journal of Shihezi University (Philosophy and Social Sciences). 2006(S1) 